\title{
Comparison of phonomyography with balloon pressure mechanomyography to measure contractile force at the corrugator supercilii muscle
}

\author{
[Comparaison de la phonomyographie et de la mécanomyographie avec ballonnet \\ sous pression pour mesurer la force contractile du muscle sourcilier]
}

Thomas M. Hemmerling MD DEAA, Guillaume Michaud, Denis Babin MSc, Guillaume Trager DESs, François Donati MD PhD FRCPC

\begin{abstract}
Purpose: Phonomyography is based on the creation of low frequency sounds during muscle contraction, which can be recorded and used for neuromuscular monitoring. In this study, balloon pressure mechanomyography, a novel method to measure the force of contraction via pressure changes in an air-filled balloon, was compared with phonomyography to determine neuromuscular blockade at the corrugator supercilii muscle.
\end{abstract}

Method: After approval of the Ethics Committee and informed consent, I 5 patients were studied. A small condenser microphone was taped to the area just above the eyebrow for phonomyography; an air-filled balloon was taped to the area just above the opposite eyebrow. After induction of anesthesia using remifentanil and propofol, a laryngeal mask airway was inserted without the aid of neuromuscular blocking agents. The facial nerve was stimulated supramaximally with single-twitch stimulation $(0.1 \mathrm{~Hz})$ using superficial electrodes placed on both temporal areas for onset and train-of-four stimulation every 12 sec during offset of neuromuscular blockade produced by mivacurium $0.1 \mathrm{mg} \cdot \mathrm{kg}^{-1}$. Onset and recovery measured by the two methods were compared using the $t$ test and agreement between phonomyography and balloon pressure mechanomyography was examined using the Bland-Altman method.

Results: Onset, peak effect, and time to reach 25\%, 75\%, and $90 \%$ of control twitch response for phonomyography vs balloon pressure method were $83 \pm 16 \mathrm{sec}$ vs $81 \pm 15 \mathrm{sec}, 80 \pm 15 \%$ vs $82 \pm 17 \%, 7.7 \pm 2.3 \min v s 7.5 \pm 2.4 \mathrm{~min}, 9.9 \pm 4.1 \mathrm{~min} v \mathrm{~s} 10.5$ \pm 4 min, and $12.6 \pm 4.3$ min vs $13.1 \pm 4.5$ min respectively without being significantly different. Mean bias was $1 \%$ with limits of agreement of -9 and $+9 \%$ of twitch height $(\mathrm{TI})$.
Conclusion: We applied a balloon pressure method to measure the force at the corrugator supercilii. Phonomyography at the corrugator supercilii shows good agreement with this modified version of mechanomyography.

Objectif : La phonomyographie repose sur la création de sons de basse fréquence pendant la contraction musculaire, sons qui peuvent être enregistrés et utilisés pour le monitorage des muscles. Dans notre étude, la mécanomyographie avec ballonnet sous pression, une nouvelle méthode de mesure de la force de contraction au moyen des changements de pression dans un ballonnet rempli d'air, a été comparée à la phonomyographie pour déterminer le bloc neuromusculaire du muscle sourcilier.

Méthode : Ayant obtenu l'accord du Comité d'éthique, notre étude a été réalisée auprès de 15 patients consentants. Un petit microphone à condensateur a été fixé juste au-dessus du sourcil pour la phonomyographie; un ballonnet rempli d'air a été fixé juste au-dessus du sourcil opposé. Après l'induction de l'anesthésie avec rémifentanil et propofol, un masque laryngé a été inséré sans aide d'agents bloqueurs neuromusculaires. Le nerffacial a subi un stimulus supramaximal simple $(0,1 \mathrm{~Hz})$ par des électrodes superficielles placées sur les deux tempes pour la stimulation du début et en train-de-quatre toutes les 12 sec pendant la récupération du blocage neuromusculaire produit par $0,1 \mathrm{mg} \cdot \mathrm{kg}^{-1}$ de mivacurium. Le délai d'installation et la récupération mesurés selon les deux méthodes ont été comparés par le test $t$ et la concordance entre phonomyographie et mécanomyographie avec ballonnet sous pression a été examinée selon la méthode Bland-Altman.

Résultats : Le délai d'installation, l'effet maximal et le temps néces-

From the Neuromuscular Research Group, Department of Anesthesiology, Centre hospitalier de l'université de Montréal (CHUM), Hôtel-Dieu, Université de Montréal, Montréal, Québec, Canada.

Address correspondence to: Dr. T.M. Hemmerling, Department of Anesthesiology, Centre hospitalier de l'université de Montréal (CHUM), Hôtel-Dieu, 3840 rue St. Urbain, Montréal, Québec H2W 1T8, Canada. Phone: 514-890-8000, ext. 14570;

Fax: 514-412-7222; E-mail: thomashemmerling@hotmail.com

This work was performed using internal departmental funds.

Accepted for publication June 30, 2003

Revision accepted November 11, 2003. 
saire pour atteindre $25 \%, 75 \%$ et $90 \%$ de la stimulation témoin avec la phonomyographie vs le ballonnet sous pression, ont été de 83 $\pm 16 \mathrm{sec}$ vs $81 \pm 15 \mathrm{sec}, 80 \pm 15 \%$ vs $82 \pm 17 \%, 7,7 \pm 2,3$ $\min v s$ 7,5 $\pm 2,4 \min , 9,9 \pm 4,1 \min v s 10,5 \pm 4 \min$ et 12,6 \pm 4,3 min vs 13,1 $\pm 4,5$ min respectivement, sans être significativement différents. Le biais moyen a été de $1 \%$ avec des limites de concordance de -9 et $+9 \%$ de la hauteur de la stimulation (TI).

Conclusion : Nous avons appliqué une méthode avec ballonnet sous pression pour mesurer la force au muscle sourcilier. La phonomyographie du muscle sourcilier a montré une bonne concordance avec cette version modifiée de la mécanomyographie.

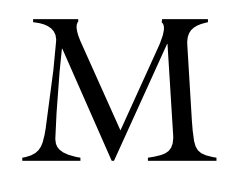

ECHANOMYOGRAPHY has long been regarded as the gold standard of neuromuscular monitoring because it measures the actual force created by muscle contraction. However, it has its limitations, notably unstable signals and difficult set-up procedures, which necessitate special arm boards. Furthermore, it cannot be used easily at several muscles of interest, such as the corrugator supercilii, which reflects neuromuscular blockade at more profound muscles, such as the larynx, better than the adductor pollicis. ${ }^{1}$ Validation of other methods of neuromuscular monitoring at the corrugator supercilii muscle have been impaired by the fact that measuring the force of contraction of this small muscle of the eyebrow is not readily possible with the same force transducers used for mechanomyography at the adductor pollicis muscle. Therefore, we have developed a mechanomyographic method similar to the method for measuring the force of contraction of the diaphragm or the adductor laryngeal muscles. ${ }^{2}$

Recently, phonomyography has been described as a new method of neuromuscular monitoring. ${ }^{3}$ The method is based on the fact that muscle contraction evokes sounds of low frequency, which can be recorded using special microphones. ${ }^{4,5}$ Initially, this method was called acoustic myography ${ }^{6,7}$ and used bulky airchamber microphones, which were difficult to apply and were unable to detect frequencies lower than 20 $\mathrm{Hz}$. Results from early studies were discrepant for this method's performance and agreement with established methods of neuromuscular monitoring. In recent studies, ${ }^{3,8,9}$ we used small condenser microphones to detect lower frequencies better. We determined signal characteristics and frequency response of neuromuscular blockade at the corrugator supercilii and could show that peak frequencies occur at 3 to 5 $\mathrm{Hz} .{ }^{3}$ We also stressed the importance of placement of

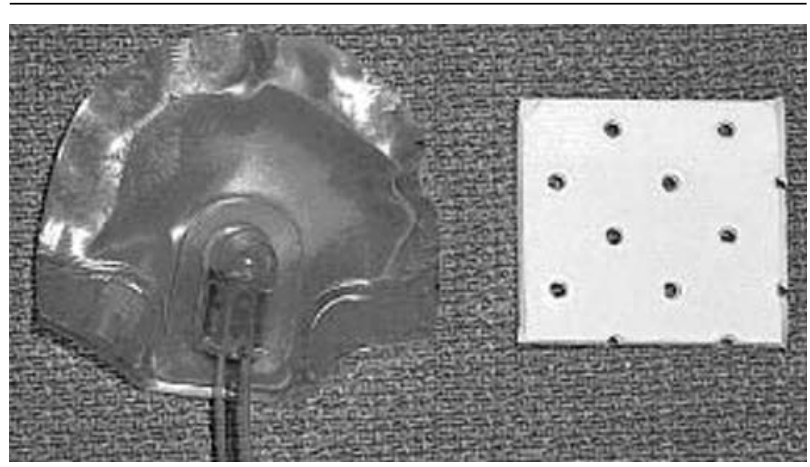

FIGURE 1A Photograph of the balloon. Pressure changes in the air-filled balloon were used to measure the force created by the contraction of the corrugator supercilii muscle. The $2.5 \times 2.5 \mathrm{~cm}$ balloon with flattened sides can be firmly glued to the skin to restrict upward movement of the balloon away from the skin.

the microphone in relation to the muscle to optimize signal recording. This study uses phonomyography to measure neuromuscular blockade at the corrugator supercilii muscle and determines its agreement with balloon pressure mechanomyography.

\section{Patients and methods}

The study was approved by the local Ethics Committee. After obtaining informed consent, 15 patients undergoing general surgery were included. Patients with co-existing neuromuscular disease or patients on medication known to interact with neuromuscular transmission were excluded.

After arrival in the operating theatre, routine monitors (non-invasive blood pressure cuff, pulse oximeter, five-lead electrocardiography) were applied. Anesthesia was induced with iv remifentanil 0.25 to $0.5 \mu \mathrm{g} \cdot \mathrm{kg}^{-1} \cdot \mathrm{min}^{-1}$ followed by iv propofol 2 to 3 $\mathrm{mg} \cdot \mathrm{kg}^{-1}$ two minutes later. After loss of consciousness and ventilation via facemask for two minutes with $100 \%$ oxygen, a laryngeal mask airway (size 4 for women, size 5 for men, Laryngeal Mask Company, Oxon, UK) was inserted and controlled ventilation commenced with minute ventilation set to maintain an end-tidal $\mathrm{PETCO}_{2}$ of 25 to $40 \mathrm{mmHg}$. Anesthesia was maintained with a 1 to 1.5 minimum alveolar concentration of sevoflurane in a mixture of $30 \%$ oxygen in air. Analgesia was provided by remifentanil 0.05 to $0.25 \mu \mathrm{g} \cdot \mathrm{kg}^{-1} \cdot \mathrm{min}^{-1}$ throughout surgery.

The contractile force of the corrugator supercilii muscle was measured using a small air-filled balloon, filled with $3 \mathrm{~mL}$ of air, connected to a pressure transducer (Figure 1). The balloon was glued to the skin to 


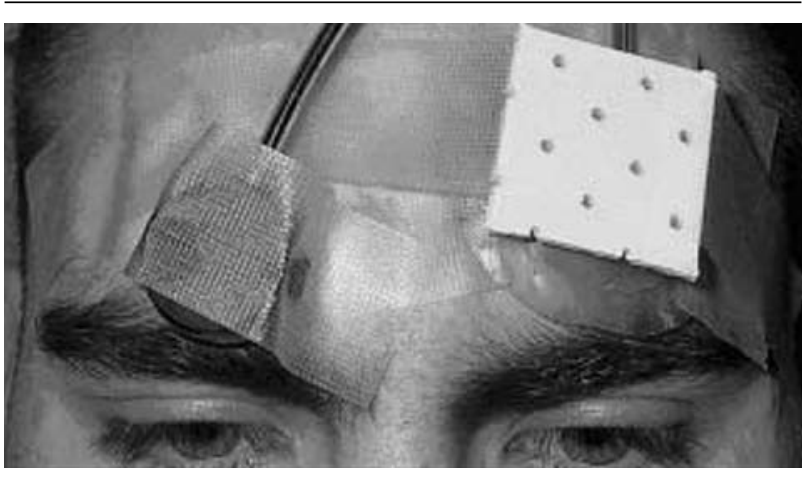

FIGURE 1B Photograph of the measurement setup. The balloon is attached to the left corrugator supercilii muscle with a small piece of plastic to restrict movement away from the skin. This prevents underestimation of the actual force and serves as a form of pre-load.

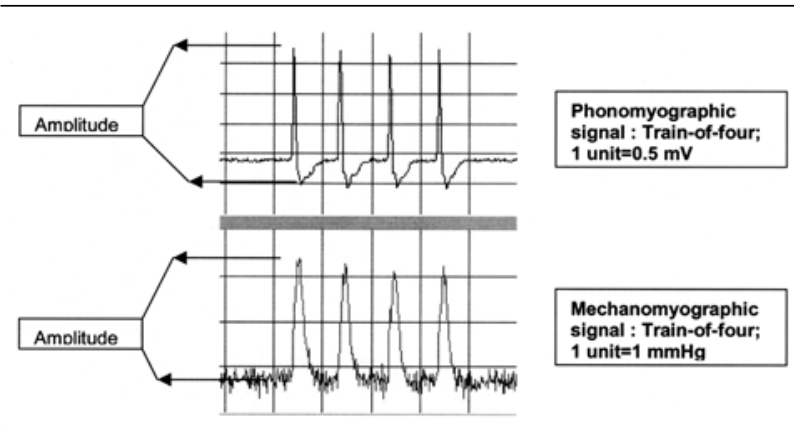

FIGURE 2 Phonomyographic and balloon pressure mechanomyographic signals after train-of-four stimulation. Arrows indicate amplitudes measured.

make sure that all the sides were completely attached to the skin in order to avoid detachment of the balloon during muscle contraction. To restrict upward movements of the balloon away from the skin, a small piece of plastic was glued on top of the balloon and tightly taped to the ipsilateral temporal forehead and contralateral frontal area. The pressure signal was amplified using an AC/DC amplifier (Model 7P122, Grass Instruments, Astra-Med Inc., West Warwick, RI, USA) and its amplitude was measured (Figure 2). Changes of intra-balloon pressure reflected muscle contractile force as described for the larynx. ${ }^{2}$

The acoustic signals produced by the contraction of the opposite corrugator supercilii muscle were record-

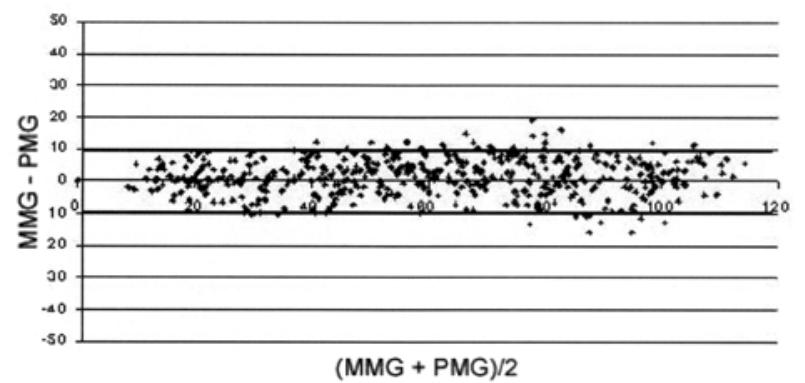

FIGURE 3A Bland-Altman test for all evoked signals. Mean bias was $1 \%$ with limits of agreement of -9 and $+9 \%$ for all signal.

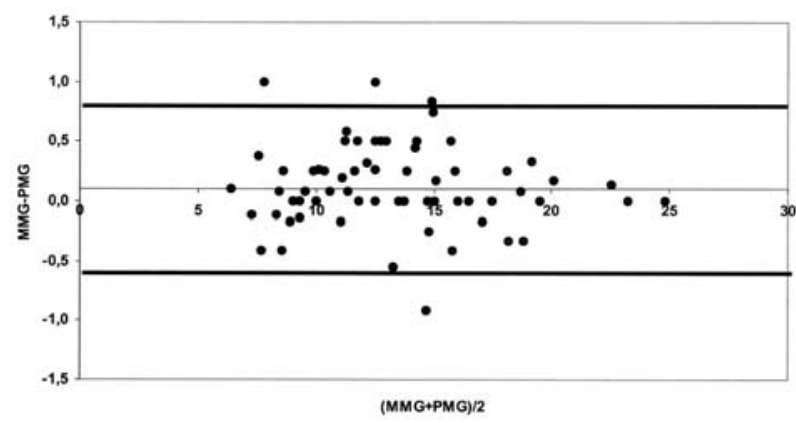

FIGURE 3B Bland-Altman test for train of four ratios $0.5,0.7$, $0.8,0.9$. Mean bias was 0.1 min with limits of agreement of -6 and +8 min. $\quad M M G=$ balloon pressure mechanomyography; PMG $=$ phonomyography.

ed as described before. ${ }^{3}$ The microphone signal was amplified and band pass filtered between $0.5 \mathrm{~Hz}$ and $1000 \mathrm{~Hz}$ using an AC/DC amplifier (Model 7Pl22, Grass Instruments, Astra-Med Inc., West Warwick, RI, USA). The signals were continuously sampled at $100 \mathrm{~Hz}$ using the Polyview ${ }^{\circledR}$ software package (AstraMed, Inc., West Warwick, RI, USA), digitized, and stored on a portable microcomputer. The singletwitch phonomyographic signal was measured peakto-peak (Figure 2).

Neuromuscular block was measured by mechanomyography and phonomyography simultaneously (Figure $1 \mathrm{~b}$ ) with a time shift of two seconds between the two sides, which was necessary to avoid measurement of contraction of the contralateral muscle. In all patients, the facial nerve was stimulated at 


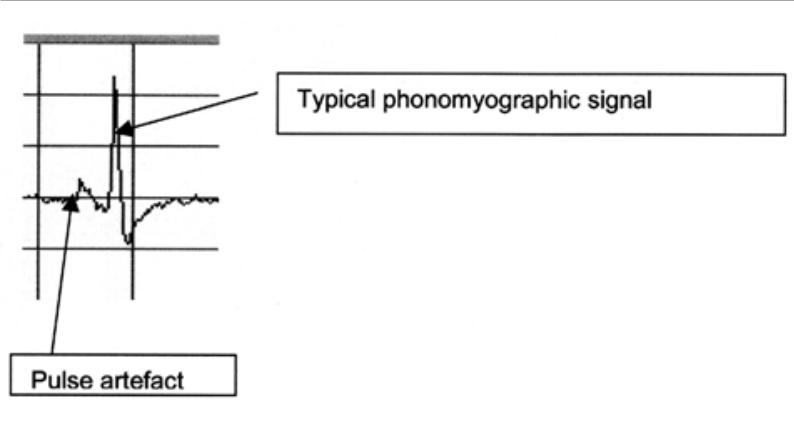

FIGURE 4 Arterial pulsation as artifact.

the temporal area after searching for the best possible stimulation site. Facial nerve stimulation in this area creates contraction of the orbicularis oculi muscle and the corrugator supercilii muscle; therefore, displacement of the stimulating electrodes to achieve optimal contraction of the corrugator supercilii muscle with minimal contraction of the orbicularis oculi muscle is important. Usually, this is done by shifting the electrodes cranially. Once the best stimulation site was found, a current of 20 to $30 \mathrm{~mA}$ was set to achieve supramaximal stimulation, which was determined using single-twitch stimulation at $0.1 \mathrm{~Hz}$. Stimulation was performed via surface electrodes using a constant current stimulator (Innervator ${ }^{\circledR}$, Fisher and Paykel Healthcare, Auckland, New Zealand) that generated single-twitch square pulses of $0.2 \mathrm{msec}$ with a current intensity between 0 and $70 \mathrm{~mA}$ [train-of-four (TOF) stimulation every $12 \mathrm{sec}$ for offset of neuromuscular blockade, with a time shift of two seconds between the two sides]. After at least five minutes of supramaximal stimulation and stable baselines for both recordings, iv mivacurium $0.1 \mathrm{mg} \cdot \mathrm{kg}^{-1}$ was injected within five seconds into a fast flowing solution of Ringer's lactate. Onset, maximal effect, and offset of neuromuscular blockade after mivacurium were determined.

The first twitch response was used to analyze the time to reach maximum decrease of twitch response (onset time), and the times to reach 25\% (T 25\%), 75\% (T 75\%), and 90\% (T 90\%) of control twitch response. The maximum effect was defined as the maximal decrease of the twitch response. Time to reach a TOF ratio of $0.5,0.7,0.8$ and 0.9 was calculated for balloon pressure mechanomyography and phonomyography simultaneously.

Sample size was calculated to detect an estimated difference of $20 \%$ of mean onset time and T 25\% between the two methods with a type I error rate of
TABLE

\begin{tabular}{lll}
\hline & $\begin{array}{l}\text { Phonomyography } \\
(n=15)\end{array}$ & $\begin{array}{l}\text { Balloon pressure } \\
\text { Mechanomyography } \\
(n=15)\end{array}$ \\
\hline Onset time $(\mathrm{sec})$ & $83 \pm 16$ & $81 \pm 15$ \\
Maximum effect $(\%)$ & $80 \pm 15$ & $82 \pm 17$ \\
T 25\% (min) & $7.7 \pm 2.3$ & $7.5 \pm 2.4$ \\
T 75\% (min) & $9.9 \pm 4.1$ & $10.5 \pm 4$ \\
T 90\% (min) & $12.6 \pm 4.3$ & $13.1 \pm 4.5$ \\
TOF ratio 0.5 (min) & $10.9 \pm 3.4$ & $11 \pm 3.5$ \\
TOF ratio 0.7 $(\mathrm{min})$ & $13 \pm 3.9$ & $13.1 \pm 4$ \\
TOF ratio 0.8 $(\mathrm{min})$ & $14 \pm 4.1$ & $14.2 \pm 4$ \\
TOF ratio 0.9 $(\mathrm{min})$ & $15.1 \pm 4.2$ & $15.2 \pm 4.2$ \\
\hline
\end{tabular}

Onset time $=$ time to reach maximum effect; $\mathrm{TOF}=$ train-of-four; Maximal effect $=$ maximum decrease in twitch height $(\mathrm{T} 1)$ in comparison to control twitch height. T $25 \%=$ time to reach $25 \%$ of control twitch height; T $75 \%=$ time to reach $75 \%$ of control twitch height; T $90 \%=$ time to reach $90 \%$ of control twitch height; All values are expressed as mean \pm standard deviation.

$5 \%$ and a power of $95 \%$. The mean difference of all signals determined using both methods (mechanomyography minus phonomyography) and the limits of agreement (LOA) between the two methods were analyzed using the Bland-Altman method. ${ }^{10}$ Correlation between the two methods was calculated using Pearson's test. Data were compared between phonomyography and balloon pressure mechanomyography using the t test. A $P$-value $<0.05$ was considered statistically significant. Data are presented as mean \pm standard deviation.

\section{Results}

In all patients, pharmacodynamic results with both methods could be obtained. Recordings of signals were continued until TOF ratios were greater than 0.9 in all patients. Typical phonomyographic and balloon pressure mechanomyographic signals are shown in Figure 2. Balloon pressure measurements were very sensitive to artifacts; any movement close to the head caused significant interference. In addition, the baseline showed substantial movement because of small signal heights making analysis of signals with small amplitudes very difficult. In order to avoid artifacts, surgery needed to be stopped during the measurements. In two patients, the balloon needed careful reattachment during the recovery period because the tape had disconnected from the skin.

Onset, maximal effect, T 25\%, T 75\%, and T 90\% were similar for both methods (Table). Correlation between the balloon pressure method and phonomyography was very good $(\mathrm{r}=0.98$ for all $\mathrm{T} 1 \%$ twitches). 
Mean bias was $1 \%(\mathrm{LOA}-9,+9 \%$ ) for all signals (Figure $3 \mathrm{a})$. There was no significant difference in the measurement of the times to reach TOF-ratios of $0.5,0.7,0.8$, and 0.9 (Table). Correlation between the balloon pressure method and phonomyography was very good with $\mathrm{r}=0.99$ for the times to reach TOF-ratios of $0.5,0.7$, 0.8 and 0.9 . Mean bias for time to reach TOF-ratios of $0.5,0.7,0.8$, and 0.9 was $0.1 \mathrm{~min}$ (LOA: $-0.6 \mathrm{~min}, 0.8$ min; Figure $3 \mathrm{~b}$ ). There was no drift ( $\mathrm{T} 1 \%$ higher at full recovery than the initial value) monitored by the balloon pressure method and only a minimal drift with phonomyography $(103 \pm 3 \%)$.

\section{Discussion}

Onset and offset of neuromuscular blockade measured using phonomyography were very close to those obtained using the balloon pressure method. Agreement between balloon pressure mechanomyography and phonomyography was very good with minimal bias. Both methods can be used interchangeably to measure onset, offset and maximum effect of neuromuscular blockade after mivacurium at the corrugator supercilii muscle. Phonomyography showed minimal drift in this study, there was no drift with the balloon pressure mechanomyography.

The advantage of phonomyography lies in the fact that it is less difficult to apply, does not need special set-up procedures, and is less prone to artifacts. This method only needs a small condenser microphone (special in its ability to record very low frequency sounds), which is taped to the region above the eyebrow and is less prone to artifacts than the balloon pressure measurements. It is clear that balloon pressure mechanomyography is not a classical "mechanomyographic" measurement using a force transducer as it is available for the adductor pollicis muscle. However, it measures force, in analogy to cuff pressure measurements of the larynx which measures force of contraction of adducting laryngeal muscles. Prior to the study we experimented with balloons of different shapes and volumes in order to find a balloon which was most suitable to measuring force of contraction of the corrugator supercilii muscle. The balloon and the form of application that was used finally in this study produced the signals with highest amplitudes and lowest baseline movements: a balloon of 2.5 $\times 2.5 \mathrm{~cm}$, rather square in shape with flattened sides that can be firmly taped to the skin. To restrict upward movement of the balloon away from the skin (and herewith underestimating the actual signal amplitude) a small additional piece of plastic, analogous to preload counterweights for classical mechanomyographic measurements of the adductor pollicis muscle, is attached firmly to bone structures of the face without movement. The balloon pressure method seemed to be too prone to artifacts and too much care needed to be taken in comparison to phonomyography for setup and careful monitoring; any movement disturbed the signal and caused slight movements. Subtle spontaneous contractions of the forehead that might occur in patients under lighter anesthesia disturb the balloon pressure monitoring. We would therefore favour phonomyography as a simple method which can be applied by just gluing a small microphone to the skin.

In a previous study, ${ }^{3}$ we have shown that phonomyography can easily be applied at the corrugator supercilii muscle, where its monitoring sensibility is better than those of acceleromyography. The fact that it can be applied at various muscles of interest in neuromuscular research (corrugator supercilii muscle, adductor pollicis muscle, adducting laryngeal muscles or diaphragm) and the good to very good agreement with methods measuring the actual force of muscle contraction (cuff pressure mechanomyography at the larynx,${ }^{8}$ mechanomyography at the adductor pollicis muscle $)^{9}$ makes it an interesting method for simultaneous monitoring of several muscles for which mechanomyography is difficult or impossible to apply.

There are still some problems with this method; since phonomyography measures low frequency sounds, artifacts are possible. Vessel pulsations can cause rhythmic sounds, which are detected as small waves of the baseline (Figure 4). However, these artifacts are easily recognizable and do not disturb the evoked measurements. Since the microphone is simply taped to the skin, care needs to be taken not to detach the tape and therefore lose the contact between the microphone and the skin surface. If this happens, the initial signal and the signal after recuperation of neuromuscular blockade are not necessarily of the same height or shape. Here, our group has begun technical improvements that may improve this situation by fitting the microphone with a self-adhesive surface, which then can be removed easily from the patient's skin, similar to electrocardiogram electrodes.

So far, we have evaluated several aspects of phonomyography. A frequency domain analysis and determination of peak frequency to identify the technical properties of the method have shown that suitable microphones need to be able to record sounds between $2 \mathrm{~Hz}$ and $50 \mathrm{~Hz} .{ }^{3}$ The duration of control stimulation does not change the measured onset, maximum effect or offset of neuromuscular blockade. ${ }^{11}$ The determination of the LOA between phonomyography and methods measuring the actual force of contraction has been very promising in showing narrow 
LOA. Our current research efforts deal with more technical questions as to whether the microphone size has an impact on sound detection and whether the size of the microphone influences measurement of neuromuscular blockade.

Balloon pressure mechanomyography correlates and agrees well with phonomyography under carefully-controlled conditions, but its baseline variability and susceptibility to artifacts from patient movements does render it impractical for routine clinical use. Phonomyography is an attractive method for routine clinical use because of its ease of application, baseline stability, and absence of elaborate devices.

\section{References}

1 Pland B, Debaene B, Donati F. The corrugator supercilii, not the orbicularis oculi, reflects rocuronium neuromuscular blockade at the laryngeal adductor muscles. Anesthesiology 2001; 95: 96-101.

2 Donati F, Plaud B, Meistelman C. A method to measure elicited contraction of laryngeal adductor muscles during anesthesia. Anesthesiology 1991; 74: 827-32.

3 Hemmerling TM, Donati F, Beaulieu P, Babin D. Phonomyography of the corrugator supercilii muscle: signal characteristics, best recording site and comparison with acceleromyography. Br J Anaesth 2002; 88: 389-93.

4 Barry DT. Muscle sounds from evoked twitches in the hand. Arch Phys Med Rehabil 1991; 72: 573-5.

5 Barry DT, Cole NM. Muscle sounds are emitted at the resonant frequencies of skeletal muscle. IEEE Trans Biomed Eng 1990; 37: 525-31.

6 Dascalu A, Geller E, Moalem $\Upsilon$, Manoah M, Enav S, $R$ udick $Z$. Acoustic monitoring of intraoperative neuromuscular block. Br J Anaesth 1999; 83: 405-9.

7 Bellemare F, Couture J, Donati F, Pland B. Temporal relation between acoustic and force responses at the adductor pollicis during nondepolarizing neuromuscular block. Anesthesiology 2000; 93: 646-52.

8 Hemmerling TM, Babin D, Donati F.

Phonomyography as a novel method to determine neuromuscular blockade at the laryngeal adductor muscles: comparison with the cuff pressure method. Anesthesiology 2003; 98: 359-63.

9 Hemmerling TM, Babin D, Donati F.

Phonomyography and mechanomyography can be used interchangeably to measure neuromuscular block at the adductor pollicis muscle. ASA Meeting Abstracts 2002; 987 (abstract).

10 Bland JM, Altman DG. Statistical methods for assessing agreement between two methods of clinical measurement. Lancet 1986; 1: 307-10.
11 Hemmerling TM, Donati F, Babin D, Beaulieu P. Duration of control stimulation does not affect onset and offset of neuromuscular blockade at the corrugator supercilii muscle measured with phonomyography or acceleromyography. Can J Anesth 2002; 49: 913-7. 